\title{
Death in detention in Sousse, Tunisia: a 10-year autopsy study
}

\author{
Maher Jedidi ${ }^{*}$ DD, Mohamed Chérif El khal', Souheil Mlayeh³, Mohamed Mahjoub², Zied Mezgar ${ }^{4}$, Tasnim Masmoudi', \\ Mohamed Ben Dhiab', Majed Zemni ${ }^{1}$ and Mohamed Kamel Souguir ${ }^{1}$
}

\begin{abstract}
Background: Mortality rates and causes of death of the detainees are hence different from those of the general population and there also vary according to regions and countries.

Aims: To study the peculiarities of death among individuals detained in the region of Sousse in Tunisia and to suggest preventive measures.

Material and methods: This is a descriptive retrospective study of all deaths in detention collated in the Forensic Medicine department of Farhat Hached teaching hospital in Sousse, Tunisia during a 10-year period 2006 to 2015.

Results: 26 deaths were collected. All the victims were males. The mean age was 39.5 years. The deaths occurred inside the prison in $42.3 \%$ and $57.7 \%$ in a hospital. The deaths were of natural causes in $69.2 \%$. The most common natural causes were cancer (6 cases, 33.3\%) and infections (5 cases,27.8\%). Violent death accounted for 31.8\% of deaths with 08 victims. Suicide and homicide were the violent death causes most incriminated each with $11.5 \%$ (3 cases). The suicide means was hanging in all cases. The death was accidental in 2 cases (7.7\%).
\end{abstract}

Conclusion: This study shows that a large proportion of deaths among prisoners are preventable. Prevention is, on the one side, by improving the prison health coverage and on the other side by training the prison staff on the identification of suicidal crises and on controlling the technical devices facilitating the transition to the suicidal act, in particular the hanging cases.

Keywords: Death, Prisons, Disease, Suicide, Tunisia

\section{Background}

It is recognized that in prisons, the harsh prison conditions, overcrowding and lack of medical care affect the prisoners' mental and physical health (Gherman \& Chiroban, 2015; Shaw \& Elger, 2015; Elger, 2008a; Elger, 2008b). Mortality rates and causes of death of the detainees are hence different from those of the general population (Gherman \& Chiroban, 2015; Alive et al., 1989). The causes of death of this vulnerable population may also vary according to regions and countries. Improving the health of prisoners and preventing mortality necessarily involves identifying and documenting the causes of death of this particular and vulnerable population.
In Tunisia, the revolution of January 2011, where a series of popular protests led to the departure of the President of the Republic in office since 1987 and allowed the gradual installation of a new political system with more freedom, helped lift the issue of prison conditions in Tunisian prisons and the question of deaths in prisons is regularly brought to the front of the media scene and sometimes to the political one. We do not currently include data on mortality of prisoners in Tunisia, despite the valuable information that data on the health of prisoners can provide.

The aim of this work is to study the peculiarities of death among individuals detained in the region of Sousse in Tunisia and to suggest preventive measures.

\section{Methods}

This is a descriptive retrospective study of all the detainees' deaths collated in the Forensic Medicine Department of 
Farhat Hached Teaching Hospital in Sousse for a period of 10 years from 2006 to 2015; we included the deaths of all detainees, even those occurring outside the place of detention.

The Forensic Medicine Department of the teaching hospital farhat hached Sousse, covers the whole region of Sousse, Tunisia and especially the civil prison of Messadine, the only prison in the region with a capacity of 2500 detainees, males and females. According to the Tunisian law, any any death in detention is considered a suspicious death that poses a forensic obstacle to burial. A judicial inquiry and an autopsy of the body are systematically performed.

Our data collection was achieved from the forensic autopsy cases (judicial requisitions, the deceased medical records, autopsy reports, complementary examination reports).

\section{Results}

\section{Cases characteristics and death circumstances}

In total 26 detainee deaths were collected, all Messadine prison detainees. A peak incidence was observed in the year 2014 with 7 deaths (Fig. 1). All the victims were males. The mean age was 39.5 years, ranging from 18 to 80 years. Among the victims 22 were convicted and 4 others were convicted on remand. The population caracteristics are presented in Table 1.

The deaths occurred inside the prison in 11 cases (42.3\%) and in a hospital in 15 cases (57.7\%).

\section{Death causes}

The death was of natural cause in 18 victims (69.2\%). The violent death accounted for $31.8 \%$ of the deaths with 08 victims. The age group has been correlated with the types of death and we founded that violent deaths were more prevalent in the 18 to 30 age group, while natural death concerned prisoners aged between 51 and 60 years.

Suicide and homicide were the most incriminated violent death causes each with 3 cases (11.5\%). The suicidal means was hanging in all cases. The death was accidental



Fig. 1 Distribution of the cases according to year
Table 1 The characteristics of the population

\begin{tabular}{lll}
\hline & $\mathrm{n}$ & Percent \\
\hline Marital Status & 12 & 46,1 \\
Single & 12 & 46,1 \\
Married & 1 & 3,8 \\
Divorced & 1 & 3,8 \\
Widower & & \\
Socio-economic Level & 16 & 61,5 \\
Low & 8 & 30,8 \\
Medium & 2 & 7,6 \\
High & & \\
Lenght of Detention & 8 & 30,8 \\
Less Than 1 year & 8 & 30,8 \\
More Than 1 year & 10 & 38 \\
Not Mentioned & &
\end{tabular}

in 2 cases $(7.7 \%)$. The nature and causes of death are shown in Fig. 2 and Table 2.

\section{Discussion}

The prisoners are under the responsibility of the authority that decided their detention and their health are a worldwide real problem and a public health priority (Ünal et al., 2016; Lines, 2008). The death rates among prisoners are often reported to be higher than among civilians (Wobeser et al., 2002; Salive et al., 1990; Dalton, 1999). We did not find any statistics or publications on deaths in the penitentiary environment in Tunisia.

The relatively low number of deaths in our series, only 26 cases can largely be explained by the common practice of sentence suspension for medical reasons for the terminally-ill prisoners according to their disease evolution. This also partly explains the young age of our population. All the victims of our series were males. The detainee environment is known to be predominantly male and the great predominance of males in death series in penitentiary environments is often reported in literature (Gherman \& Chiroban, 2015; Ünal et al., 2016; Wobeser et al., 2002).

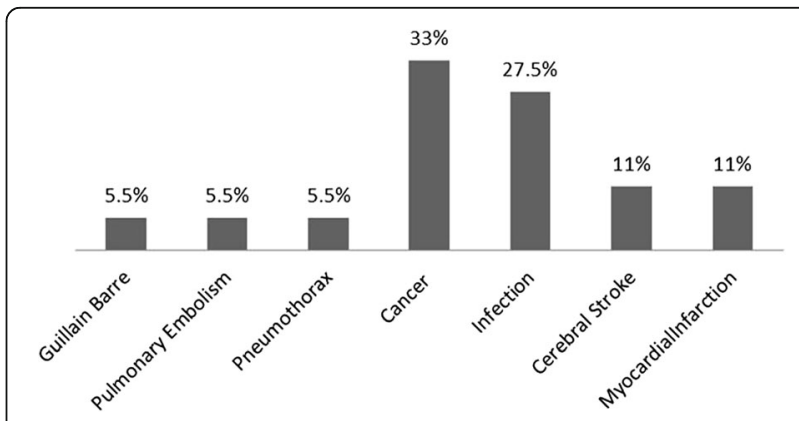

Fig. 2 Distribution of deaths of natural causes 
Table 2 Distribution of deaths of violent causes

\begin{tabular}{|c|c|c|}
\hline & $n$ & Percent \\
\hline \multicolumn{3}{|l|}{ Accident } \\
\hline Médiastinitis ${ }^{\mathrm{a}}$ & 1 & 12,5 \\
\hline Cafe coronary & 1 & 12,5 \\
\hline \multicolumn{3}{|l|}{ Homicide } \\
\hline Gunshot wounds & 3 & 37,5 \\
\hline \multicolumn{3}{|l|}{ Suicide } \\
\hline Hanging & 3 & 37,5 \\
\hline Total & 8 & 100 \\
\hline
\end{tabular}

${ }^{\mathrm{a}}$ Mediastinitis complicating swallowed razor blade

Most victims had a low socio-economic level (17 cas). This is the context of poverty which is conducive to crime committing and which often explains the detention and conviction (Yapo Etté et al., 2012; Okoye et al., 1999; Faget, 2013).

Regarding the cause of death, the majority of deaths $(18 / 26)$ were of natural causes. It is related to the conditions of detention in Tunisian prisons. An April 2014 report, Prisons in Tunisia: International Standards versus Reality, by the UN Office of the High Commissioner for Human Rights, cited overcrowding, along with poor infrastructure, as the biggest problems in prisons (Kim et al., 2007). Worldwide, the literature shows a wide variety of causes of death of detainees often with a predominance of natural causes. Thus, and as in our series, in penitentiary facilities in Atlanta, Georgia, between 1974 and 1985, the majority of deaths among prisoners were due to natural causes ("Prisons in Tunisia: International Standards versus Reality", UN Human Rights Watch report, 2014), and Saliva et al. also reported that over $68 \%$ of all deaths in the prison system of Maryland on an 11-year study period were due to diseases (Alive et al., 1989). Studies in India between 2001 and 2010 in Turkey between 2010 and 2012 also revealed that the vast majority of deaths in custody were of natural causes with 90\% (Frost \& Hanzlick, 1988) and $83.2 \%$ (Ünal et al., 2016). In contrast, in Canada, a study in Ontario between 1990 and 1999 showed that more than half of the deaths in custody were of violent causes (Wobeser et al., 2002).

The most common cause of natural deaths in our series was due to cancers (33.3\%) followed by infections (27.8\%). This correlated with the literature data. Indeed, cancer has accounted for $23.07 \%$ of natural causes after cardiovascular causes with $42.3 \%$ in a recent Turkish study (Ünal et al., 2016). Similarly in the US between 2000 and 2013, in American prisons, they found that $79.6 \%$ of deaths were secondary to natural causes, and among them $30.5 \%$ were of cardiac cause and $26.3 \%$ of tumor origin (Bardale \& Dixit, 2015). Cardiovascular causes accounted for only $16.7 \%$ of natural causes in our series with two cases of myocardial infarction and pulmonary embolism. The young age of our population partly explains this low proportion compared to foreign series.

In our study there were three suicides $11.5 \%$. In the international literature, the suicide rates among prisoners vary. Thus, a survey of all American prisons indicated that suicide is the second cause of death of prisoners, after the natural cause of death, with 12.09\% (Bardale \& Dixit, 2015). In contrast, in Canada, $31.16 \%$ of prisoners' cause of deaths in Ontario between 1990 and 1999 were suicide (Wobeser et al., 2002). The mean age of suicide victims in the study were 25 years old. In the prisons of New York, 21\% of deaths by suicide among prisoners concerned those aged between 25 and 29 years, and 26\% were between 30 and 34 (Margaret, 2015). Also in the Finnish and Australian studies, suicide was more common in younger prisoners (Marcus \& Alcabes, 1993; Joukamaa, 1997). Saliva et al. (Alive et al., 1989) reported that the relative risk of suicide among prisoners aged between 25 and 34 years was significantly higher than in any other age group.

Hanging was the means exclusively used by the prisoners of our study who committed suicide. This finding correlated with the literature data reporting that hanging is a frequent means of suicide in prisons (Wobeser et al., 2002; Yapo Etté et al., 2012; Okoye et al., 1999). The feasibility of including hanging in a closed environment may explain this finding.

The place of detention can influence suicidal detainees. In our series, the 3 suicides which occurred in prison was committed by three individuals who had already been condemned and purged their sentences. An Indian study on suicides in detention, found that more than $71 \%$ of suicides occurred in police stations and $36 \%$ of suicides occurred within $24 \mathrm{~h}$ following the arrest (Wobeser et al., 2002). The custody period may also influence the detainees' passage to suicidal act. In the literature, the findings vary, the studies have shown that the mortality rate increases proportionately with the duration of the detention and other studies concluded to the contrary (Alive et al., 1989; Coffey et al., 2003; Topp, 1979).

Other than suicide, the causes of violent deaths in our study were homicides by firearms and accidents. We collected three homicide cases (11.5\%). In American prisons homicides, including accidental homicide due to the use of violence by the guards, accounted for $1.9 \%$ of causes of death of prisoners between 2000 and 2013. All homicide cases in our study were involuntary, occurring as a result of gunshot wounds in the aftermath of riots and escape attempts during the revolution of 2011. No case of murder was found. Only two cases of accidental death were found. In the literature after the suicide by hanging, death by substance abuse, which includes cases of poisoning and 
overdose among consumers of hard drugs and homicides are the main cause of violent deaths among prisoners (Gherman \& Chiroban, 2015; Wobeser et al., 2002; Smialek \& Spitz, 1978).

\section{Conclusion}

Despite the small sample size, our study showed that many of the deaths of prisoners are preventable deaths. Preventing these deaths through improving prison health coverage and facilitating the hospitalization of prisoners in hospital or founding prison medical facilities, which would allow, on the one side, a rapid diagnosis of infections and on the other hand an early diagnosis of cancers. For suicides in prison, prevention requires the training of prison staff in the detection of suicidal crises and control of technical devices possibly facilitating the transition to the suicidal act especially the one by hanging. We suggest similar studies in other Tunisian regions, to increase the scale of research and to have more valuable results in order to implement a National Program to prevent delays in prosecuting cases and to respect human rights of prisoners.

\section{Acknowledgements}

No one

Funding

No one.

\section{Availability of data and materials}

Data of the study was obtained from the files of forensic autopsy of the departement of Legal Medicine of Farhat Hached University Hospital of Sousse. they can not be shared for legal reasons.

\section{Author's contributions}

JM, MS, ZM and MCEK made contributions to the conception, acquisition of data, analysis and interpretation of data; JM, MM, TM and BDM have been involved in drafting the manuscript and revising the content; JM, MZ and MKS have given final approval of the version to be published. All authors read and approved the final manuscript.

\section{Authors' information}

- All the authors of the study are doctors of the hospital Farhat Hached de Sousse, university center, which receives and ensures the medical care to large part of the detainees of the region.

- Some of these authors are forensic pathologist at the department of legal medicine of this hospital. This receives all the corpse of deads detainee in the region of Sousse.

\section{Ethics approval and consent to participate}

This study was approuved by the ethics committee of Farhat Hached university hospital of Sousse, Tunisia.

\section{Consent for publication}

Not applicable

\section{Competing interests}

The authors declare that they have no competing interests.

\section{Author details}

'Department of legal medicine, Farhat Hached University Hospital, 4000 Sousse, Tunisia. ${ }^{2}$ Department of hospital hygiene, Farhat Hached University Hospital, Sousse, Tunisia. ${ }^{3}$ Department of legal medicine, Ibn Jazzar University Hospital, Kairouan, Tunisia. ${ }^{4}$ Department of emergency medicine, Farhat Hached University Hospital, Sousse, Tunisia.

Received: 2 October 2017 Accepted: 23 January 2018

Published online: 29 January 2018

\section{References}

"Prisons in Tunisia: International Standards versus Reality", UN Human Rights Watch report, 2014 accessed on: http://www.ohchr.org/EN/NewsEvents/ Pages/ReportsOnStateOfPrisonsInTunisia.aspx

Alive ME, Smith GS, Brewer TF. Suicide mortality in the Maryland state prison system, 1979 through 1987. JAMA. 21 juill 1989;262(3):365-369

Bardale RV, Dixit PG (2015) Suicide behind bars: a 10-year retrospective study. Indian J Psychiatry mars 57(1):81-84

Coffey C, Veit F, Wolfe R, Cini E, Patton GC. Mortality in young offenders: retrospective cohort study. BMJ. 17 mai 2003;326(7398):1064

Dalton V (1999) Death and dying in prison in Australia: national overview, 1980-1998. J Law Med Ethics J Am Soc Law Med Ethics 27(3):269-274 210

Elger BS (2008a) Towards equivalent health care of prisoners: European soft law and public health policy in Geneva. J Public Health Policy juill 29(2):192-206

Elger BS (2008b) Research involving prisoners: consensus and controversies in international and European regulations. Bioethics mai 22(4):224-238

Faget J (2013) Sociologie de la délinquance et de la justice pénale. Éditions Érès, Toulouse

Frost R, Hanzlick R. Deaths In custody. Atlanta City jail and Fulton County jail, 1974-1985. Am J Forensic Med Pathol sept 1988;9(3):207-211

Gherman C, Chiroban O (2015) Causes of death among detainees: a statistical study on the casework of the forensic medicine Institute in Cluj-Napoca during the period 2000-2014. Clujul Med 88(3):314-320

Joukamaa M. Prison suicide in Finland, 1969-1992. Forensic Sci Int 6 oct 1997:89(3):167-174

Kim S, Ting A, Puisis M, Rodriguez S, Benson R, Mennella C et al (2007) Deaths in the Cook County jail: 10-year report, 1995-2004. J Urban Health Bull N Y Acad Med janv 84(1):70-84

Lines $R$ (2008) The right to health of prisoners in international human rights law. Int J Prison Health 4(1):3-53

Marcus P, Alcabes P (1993) Characteristics of suicides by inmates in an urban jail. Hosp Community Psychiatry mars 44(3):256-261

Margaret E. Noonan,. Mortality in Local Jails and State Prisons, 2000-2013 Statistical Tables [Internet]. U.S. Department of Justice, Office of Justice Programs, Bureau of Justice Statistics; 2015. Accessed on: www.bjs.gov/ content/pub/pdf/mljsp0013st.pdf

Okoye M, Kimmerle EH, Reinhard K (1999) An analysis and report of custodial deaths in Nebraska, USA. J Clin Forensic Med juin 6(2):77-84

Salive ME, Smith GS, Brewer TF (1990) Death in prison: changing mortality patterns among male prisoners in Maryland, 1979-87. Am J Public Health déc 80(12):1479-1480

Shaw D, Elger B (2015) Improving public health by respecting autonomy: using social science research to enfranchise vulnerable prison populations. Prev Med mai 74:21-23

Smialek JE, Spitz WU. Death behind bars. JAMA. 1 déc 1978;240(23):2563-2564

Topp DO (1979) Suicide in prison. Br J Psychiatry J Ment Sci janv 134:24-27

Ünal V, Özgün Ünal E, Çetinkaya Z, Imalı M, Gürler S, Koç S (2016) Custody and prison deaths autopsied in Istanbul between 2010 and 2012. J Forensic Leg Med avr 39:16-21

Wobeser WL, Datema J, Bechard B, Ford P (2002 Nov 12) Causes Of death among people in custody in Ontario, 1990-1999. CMAJ 167(10):1109-1113

Yapo Etté H, Djodjo M, Botti K, Ebouat KMEV (2012) Qu'en est-il des décès en garde à vue à Abidjan ? Étude rétrospective sur 8ans (2001-2008). Rev Médecine Légale 3:27-33

\section{Publisher's Note}

Springer Nature remains neutral with regard to jurisdictional claims in published maps and institutional affiliations. 